Article

\title{
Small Hydropower Plants with Variable Speed Operation-An Optimal Operation Curve Determination
}

\author{
Dariusz Borkowski ${ }^{1, *(1)}$ and Marek Majdak ${ }^{2}$ \\ 1 Institute of Electromechanical Energy Conversion, Cracow University of Technology, 31-155 Krakow, Poland \\ 2 Department of Energy, Cracow University of Technology, 31-155 Krakow, Poland; marek.majdak@pk.edu.pl \\ * Correspondence: dborkowski@pk.edu.pl
}

Received: 2 October 2020; Accepted: 25 November 2020; Published: 26 November 2020

check for updates

\begin{abstract}
In recent times, much attention has been paid to small hydropower plants (SHPs) with variable speed operation and different control techniques. Control complexity in SHPs is mainly caused by specific steady-state features of the water turbine, the long time constants of the hydraulic system and significant seasonal and/or aging-related deterioration in the system performance. This paper presents the most important features of the turbine model from a control point of view. It classifies control techniques for SHPs with variable speed operation in terms of the turbine type and SHP function (run-of-the-river and reservoir). Furthermore, various control methods are analysed taking into account the complexity of the method, dynamics, adaptability and applicability. The novelty of this study is the proposal of a simple, universal analytical formula, which, based on the basic dimensions of the turbine, determines the optimal operating curve. The proposed formula is verified on a real SHP $150 \mathrm{~kW}$ by comparison with measurements in the form of operational characteristics. The analysis of the annual energy production confirms the effectiveness of the approximation precision, yielding only $1 \%$ production losses, and shows an advantage of variable speed over constant speed in annual energy production of $16 \%$.
\end{abstract}

Keywords: AC-AC converters; control design; hydroelectric power generation; power generation control; hydraulic systems; variable speed drives

\section{Introduction}

Most of the local resources allowing the construction of high-power hydropower plants in Europe, as well as in the remaining parts of the world have been already utilised. Moreover, their construction costs and adverse influence on nature limit the number of new facilities. Therefore, attention has shifted to low-power schemes, i.e., under $10 \mathrm{MW}$, which are also called small hydropower plants (SHPs) [1-5]. Their positive role in the power system endows much importance to low-power hydropower plants. Similar to other types of renewable energy sources, such as photovoltaic systems and wind power plants, they belong to the class of distributed energy sources, which diversify the energy market and decrease transmission losses [6]. At times when there is a high contribution of variable renewable energy (VRE) sources to the total production of electrical energy, the negative influence of sources, characterised by high dynamics of production, on the entire system is significant [7]. This can cause a temporary overload in transmission lines and stability problems. Hydropower plants are characterised by a higher stability of energy production when compared to other renewable energy sources mentioned above. Moreover, hydropower plants with reservoirs can additionally accumulate energy [8] and thus can play an important role in hybrid power systems with VRE sources [9].

The modern solutions for water turbines decrease the production costs of hydro-sets (water turbines with a guide vane governor); furthermore, power electronic converters (PECs), which are widely available, can increase the productivity of hydropower plants by using the principle of variable 
speed operation [10] (Figure 1). The variable speed technique used in power generation systems with wind turbines is an attractive alternative for conventional hydropower systems operating at a constant speed [11]. Control over the speed allows adjustments in the operation parameters of the hydro-set (e.g., guide vane angle $-\alpha$ ) to mimic the actual hydrological conditions (e.g., water head- $H$, turbine discharge- $Q$ ) [12]. This is especially important in low-power systems, where investment and exploitation costs can be reduced by using simple propeller turbines with fixed rotor blades. The possibility of adjusting speed to mimic actual hydrological conditions widens the operating range of such hydro-sets and increases their efficiency at operating points far from the nominal values [13]. This approach enhances the production of electrical energy. Such solutions require, however, the use of a PEC to match the parameters of the generated energy to the power system requirements. Unfortunately, the presence of power electronics in the energy conversion chain decreases the total efficiency of the system [14]. On the other hand, permanent magnet synchronous generators (PMSGs), which increase the total efficiency of the system owing to the high efficiency of the generator across a wide load range, may be employed. One advantage of such generators is their design with a high pole pair number, which allows the elimination of mechanical transmission gears. Furthermore, this solution offers the possibility of integrating a water turbine with an electrical generator by inserting turbine blades into the generator rotor [15].

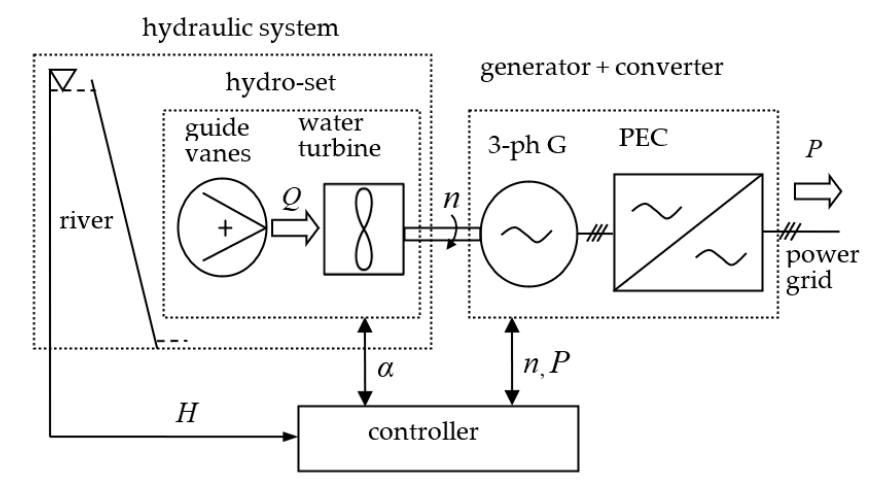

Figure 1. Schematic diagram of the energy conversion system of a variable speed small hydropower plant (SHP).

Controlling an SHP working at variable speeds is different from controlling wind systems due to the specific steady-state features of the water turbine, long time constants of the hydraulic system, water waving, energy storage possibilities and significant seasonal and/or aging-related deterioration in the system performance [16-18]. Moreover, there exist control constraints, resulting from regulating specific hydrological parameters (water level or water flow) within certain limits. Control complexity issues in SHPs imply that the popular control techniques used in wind systems may not be effective. Therefore, this paper points out the most important elements of the hydropower model and classifies (systemise) the control techniques used for SHPs with variable speed operation depending on the turbine type and SHP function (run-of-the-river and reservoir).

Recently, a number of control techniques have been developed for low-power hydropower systems with variable speed operation. As presented in the paper, most of these studies analysed energy conversion systems with a specific water turbine modelled in a simplified manner or by empirical formulas. This can be one of the main reasons for the ineffectiveness of the methodology because the turbine influences the features of the system the most significantly compared to the power electronic converter and generator $[19,20]$. From the above, it follows that there is a need to replace the empirical formulas usually used to identify the optimal operating curve valid only for a specific turbine type by a universal analytical formula. The novelty of this study is the proposal of a simple analytical formula that is universal for axial-flow turbines based on the basic turbine dimensions. The proposed formula is verified on a real SHP of $150 \mathrm{~kW}$ [15] by comparing it with measurements in the form of performance 
characteristics and the annual energy production. In addition, the efficiency of a turbine operating at constant and variable rotational speed is also compared.

\section{Hydro-Set Features}

\subsection{Non-Regulated Turbine}

The steady-state features of a turbine depend on its construction, where the geometric proportions are usually characterised by the specific speed $n_{s}$ [21], $n_{s}<200$-slow (Francis), $n_{s} \approx 350$-normal (Kaplan), $n_{s}>500$ —fast (propeller) [22].

$$
n_{s}=n_{N} \frac{\sqrt{P_{N}}}{H_{N}^{5 / 4}}
$$

Here, $n_{N}(\mathrm{rpm})$ is the nominal speed, $P_{N}(\mathrm{~kW})$ is the nominal power and $H_{N}(\mathrm{~m})$ is the nominal water head.

In order to address the differences between these three turbine types, their relative variables, including efficiency, discharge, torque and power are compared. Figure 2 presents the results of comparison under the assumption of a constant guide vane angle and runner blades (the so-called non-regulated turbine) and constant water head. The nominal operating point (discharge, power and torque) is defined for maximal efficiency. The main differences lie in the discharge curves (Figure 2a), which have a significant influence on the control over the water level.

(a)

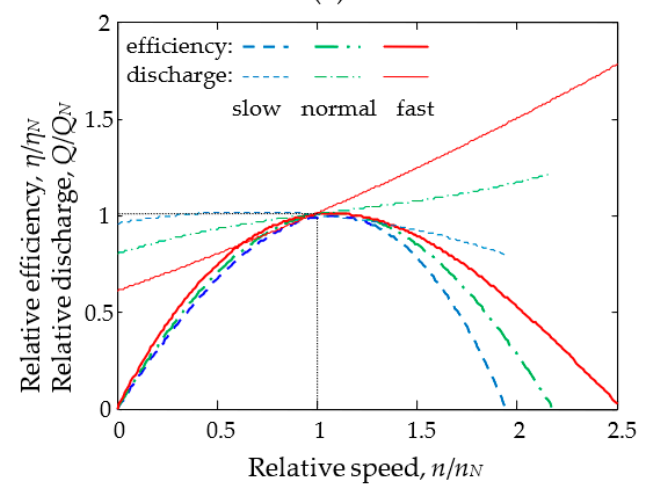

(b)

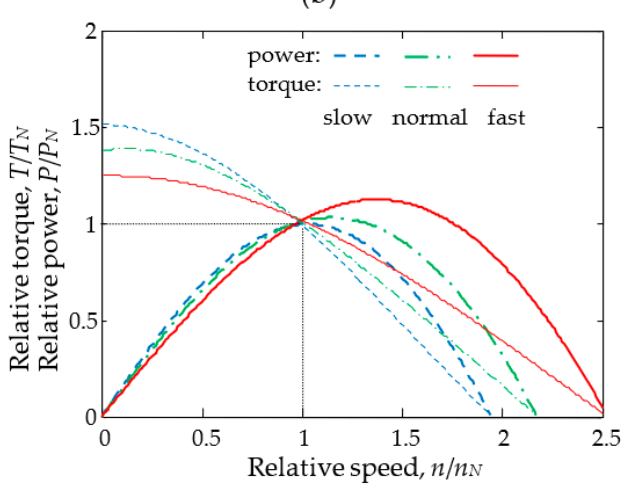

Figure 2. Comparison of non-regulated turbine (slow, normal and fast) features using relative variable curves. (a) Efficiency and discharge and (b) power and torque

The second important feature is the localisation of maximal power, which in turn is related to maximal efficiency (Figure 2b). These two points lie close to each other in the case of slow turbines; however, the distance between them increases with an increase in the specific speed. This means that the speed value for maximal power and maximal efficiency differ significantly, especially in the case of fast turbines.

\subsection{Single-Regulated Turbine}

In order to improve turbine features (to widen the operating range and increase efficiency), the guide vane angle needs to be controlled (the so-called single-regulated turbine). In this case, turbine features can be modelled using the two nonlinear equations shown in Equation (2), where $Q$, the turbine discharge, and torque $T$ are functions of head $H$, speed $n$ and guide vane angle $\alpha$.

$$
Q=f_{Q}(H, n, \alpha), T=f_{T}(H, n, \alpha)
$$


The representation of turbine steady-state features becomes difficult when the guide vane angle varies; this is usually accomplished using the so-called hill diagram, which represents efficiency contour lines on a discharge-speed plane [23]. Furthermore, to correlate the head and turbine size, double-reduced variables (normalised to the unitary head $n_{11}$ and diameter $Q_{11}$ ) Equation (3) are used.

$$
n_{11}=\frac{n \cdot D}{\sqrt{H}}, \quad Q_{11}=\frac{Q}{D^{2} \sqrt{H}}
$$

Here, $D(\mathrm{~m})$ is the turbine diameter. Example hill diagrams of the three turbine types are presented in Figure 3. They show efficiency contour lines (thin solid lines), guide vane angle curves (thick dashed lines) and three possible operating curves, i.e., a curve that connects the maximal efficiency for a given angle (red dashed line), a curve showing the maximal power points at a given angle (blue dotted line) and the optimal operating curve (green solid line). The optimal operating points (optimal speed $n_{\text {opt }}$ ) are obtained at $\eta\left(n_{\text {opt }}, Q\right)=$ maximum, which indicates maximal efficiency for a given turbine discharge. Analysis of the three hill diagrams indicates that these free operating curves are very different, especially in the case of fast (Figure 3a) and normal turbines (Figure 3b). This result implies that the chosen operating curve affects the production results. Energy production is maximum when the power is maximal (corresponding to the maximal efficiency) for a given discharge (optimal operating curve). These examples show that the control methods (operating curve) of a single-regulated turbine are different from those of a non-regulated turbine, and the maximisation of efficiency or power at a constant angle can be justified only for slow turbines.

(a)

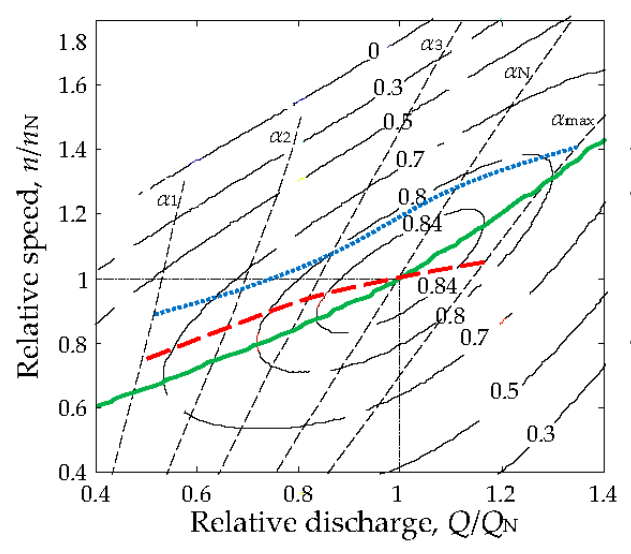

(b)

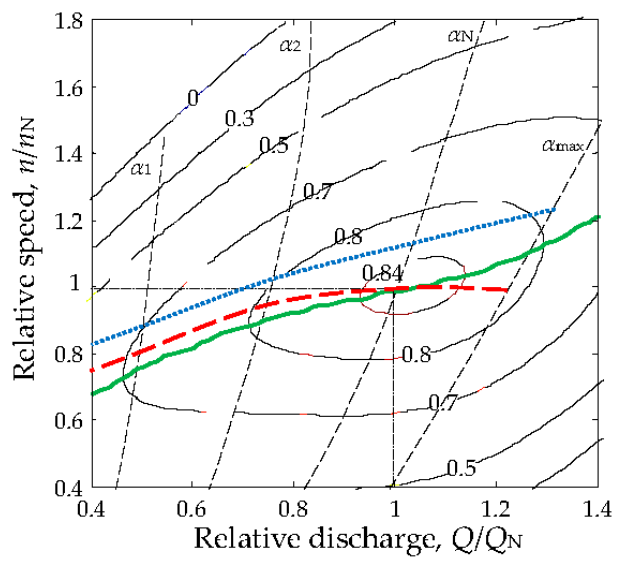

(c)

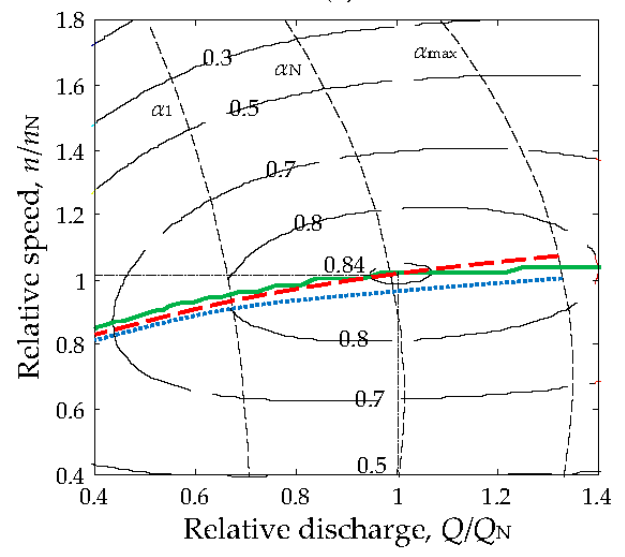

Figure 3. Hill charts of a (a) fast turbine, (b) normal turbine and (c) slow turbine showing the optimal operating curve (green solid line), maximal efficiency for a given angle (red dashed line) and maximal power for a given angle (blue dotted line). 


\subsection{Dynamics of a Hydraulic System}

The dynamic features of an SHP hydraulic system are mainly influenced by the dominant time constant of the water mass that fills the inlet and outlet pipes and turbine chamber. This time constant can be determined using the water head $H(\mathrm{~m})$, turbine discharge $Q\left(\mathrm{~m}^{3} / \mathrm{s}\right)$, pipeline length $L(\mathrm{~m})$, average cross-section of the pipeline $A\left(\mathrm{~m}^{2}\right)$ and gravitational acceleration $g\left(9.81 \mathrm{~m} / \mathrm{s}^{2}\right)$ according to Equation (4) [16].

$$
\tau_{w}=\frac{Q}{g H} \frac{L}{A}
$$

To simplify the analysis, this water time constant Equation (4) can be included in the moment of inertia $J$ of the mechanical Equation (5)

$$
J \frac{d \omega}{d t}=T_{t}-T_{e m}, J=\frac{P_{N}}{\omega_{N}^{2}}\left(\tau_{w}+\tau_{g}\right)
$$

where $T_{t}$ is the turbine torque, $T_{e m}$ is the electromagnetic torque of the generator, $P_{N}$ is the nominal system power, $\omega$ is the mechanical angular speed and $\tau_{g}$ is the generator time constant.

In the case of a long penstock that provides water to turbines and surge tanks in a hydraulic system, Newton's second law for a fluid element (differential motion equation for a transient flow) and mass conservation law for a control volume (continuity differential equation) should be adopted [16]. The influence of the hydraulic system with a surge tank on the control system was described in [24]. It was shown that the surge tank causes system oscillation, and the parameters of the water level regulator need to be carefully selected in order to optimise system stability.

The guide vane angle is usually controlled by a fluid drive system. Its speed of movement is determined by the fluid pressure, which is maintained constant. Thus, the guide vane governor can be modelled as a speed limiter with specific rising and falling slew rates [20] or as a first-order equation [16].

\section{Control Techniques}

An important aspect affecting the operational profitability of variable speed SHPs is the selection of the optimal operation curve. This curve is usually defined by speed as a function of turbine discharge and head $n_{\text {opt }}=f(Q, H)$ to provide the highest possible efficiency for a given set of hydraulic conditions. A number of techniques are available to identify this optimal curve; they can be divided into three main groups-indirect, direct and hybrid methods.

\subsection{Indirect Methods}

Indirect methods use the knowledge available on SHP features in the form of analytical relations or databases, including information on hydro-set characteristics obtained by measurements of real objects and model research.

\subsubsection{Analytical Turbine Model}

In the literature, some simplified formulae describing the correlation among the optimal speed, power and water head for a given turbine can be found [25]. However, these simple equations cannot be generalised to other turbine types. On the other hand, more precise models use the efficiency function of the turbine as the base for determining the optimal speed approximated by mathematical equations of power and discharge. A number of analytical models of water turbines are known, including a simplified nonlinear model, linearized to a given operating point based on prototype characteristics, a linear model based on turbine dimensions and a nonlinear ideal (loss-free) model $[26,27]$. The simplified nonlinear models define power as a linear function of discharge (after eliminating the no-load flow and multiplied by efficiency) $\left(P \sim\left(Q-Q_{0}\right) \eta\right)$, whereas turbine discharge is represented by the valve characteristic, $Q \sim \sqrt{H}[28,29]$. This model is usually valid at constant 
speeds. Some modifications to the efficiency [30] or the head [31] of the turbine model depending on the rotational speed are sometimes introduced, but they are based on empirical functions. Speed dependence can be introduced in the linearized model Equation (6) obtained by the Tylor series approximation of Equation (2).

$$
\begin{aligned}
Q & =\frac{\partial Q}{\partial H} H+\frac{\partial Q}{\partial n} n+\frac{\partial Q}{\partial \alpha} \alpha \\
T_{t} & =\frac{\partial T_{t}}{\partial H} H+\frac{\partial T_{t}}{\partial n} n+\frac{\partial T_{t}}{\partial \alpha} \alpha
\end{aligned}
$$

The partial derivatives of torque and discharge with respect to the head $H$, speed $n$ and guide vane angle $\alpha$ are called turbine transfer coefficients. The accuracy of the turbine coefficient that represents turbine nonlinear characteristics is critical. As described in [26], the coefficients should be recalculated for different operating points, and therefore, this model is recommended for low speed variations. A model based on the Francis turbine and including six partial derivatives was used in [16] in order to simulate transients in hydropower plants. The turbine model can also be defined using an analytical nonlinear efficiency equation. A simplified efficiency equation of discharge $Q$ and angular speed $\omega$ Equation (7) was used for a bulb turbine in [32].

$$
\eta(Q, n)=1-|\omega-Q|^{1.25}
$$

A more complex empirical Equation (8) for the propeller turbine efficiency function, relating the turbine radius $R(\mathrm{~m})$ and the area swept by rotor blades $A\left(\mathrm{~m}^{2}\right)$, was proposed in [33].

$$
\eta\left(\lambda_{t}, Q\right)=Q \cdot\left[\frac{3.33}{2}\left(\frac{90}{\lambda_{t}}+Q+0.78\right) \exp \left(\frac{-50}{\lambda_{t}}\right)\right]
$$

Here, $\lambda_{t}=\left[\frac{1}{\lambda+0.089}-0.0035\right]^{-1}$ and $\lambda=\frac{R A \omega}{Q}$.

This equation was used in a number of studies [34-37] to model turbine steady-state features in SHP control algorithms. All these studies assumed a non-regulated turbine working at a constant head, which means that the turbine discharge, as well as torque and power are functions of only one variable: speed $(Q, T, P \sim n)$. Thus, the discharge variable is dependent on speed and cannot be modified freely; the relationship $Q=f(n)$ should be used to accurately calculate the efficiency in Equations (7) and (8). Some of the studies misinterpreted this formula and presented it inaccurately as a set of curves that can influence the control methodology.

An efficiency Equation (9), based on the assumption of polynomial approximation of power and head in the correlation between the speed and discharge of a turbine, was presented in [38], where $\rho\left(\mathrm{kg} / \mathrm{m}^{3}\right)$ is the water density and $A, B, C$ are polynomial coefficients.

$$
\eta(Q, n)=\frac{P(Q, n)}{\rho g H(Q, n) Q}=\frac{A_{P} Q n^{2}+B_{P} Q^{2} n}{\rho g\left(A_{H} Q^{3}+B_{H} Q^{2} n+C_{H} Q n^{2}\right)}
$$

This analytical formula used to calculate turbine efficiency can be also obtained using a neural network model (polynomial function). In [20], the efficiency function of the propeller turbine was approximated using a multi-layer perceptron (MLP) network, where the input data parameters included the turbine speed, discharge and guide vane angle. The best approximation results of the nonlinear functions were obtained with a sigmoidal activation function in the hidden layer and a linear function in the output layer. The presented network was trained and validated using measurements from a real SHP [15].

The chosen SHP model, due to the aspects of system complexity and multivariable dependence, should be optimal from the objective control function point of view. Usually, the efficiency variable is maximised, and hence, the efficiency function of speed and discharge $\eta=f(Q, n)$ should be approximated with high accuracy. The supplementary discharge function can be approximated using 
the polynomial equation correlating the speed and guide vane angle, $Q=f(n, \alpha)$. This approach ensures model precision even with highly variable speeds and facilitates coefficient identification by measurement.

\subsubsection{Look-Up Table}

A turbine model can also be based on look-up tables in which experimental measurements are stored. In [39], the efficiency and discharge values were provided by two tables as functions of the runner blade, guide vane angles (double-regulated turbine) and speed. A model of the Kaplan turbine based on a look-up table was presented in [40]. Two tables that stored discharge and efficiency as functions of guide vane and runner angles contained the measured data, as well as the calculated data. The efficiency and discharge curves were determined by cubic spline interpolation. The drawback of this model is its validation at low speed turbine disturbances.

A control strategy based on efficiency sourced from a look-up table was presented in [41]. In this case, the table was filled in not only with the experimental data, but also with the simulation results of a neural axial-flow propeller turbine model. Simulation was performed under a constant water head and guide vane angle condition; thus, the maximum efficiency for a given angle can be different from the optimal operation curve as described in Section 2. In the look-up table method, usually one output is determined by the linear interpolation of neighbouring table data [16], and thus, a low data resolution significantly increases model error.

\subsubsection{Based on the Hill Diagram}

The SHP control algorithm can be based on experimentally determined hill diagrams. In [42], a guide vane governor was used to adjust the angle to achieve the maximal efficiency operating point given in the hill chart of the Kaplan turbine. The drawback of this solution is that it neglects the influence of the generator and PEC on the total efficiency and the optimal operating curve. A similar approach was presented in [43], where the hill diagram was used to calculate the optimal operating curve. However, in this application, the optimal speed points were obtained from a neural network, which calculated the speed based on the flow and guide vane angle. Additionally, a sigmoid function was used to smooth the reference speed signal.

The indirect methods presented above are characterised by easy implementation and high control dynamics. However, hydro-set features can vary with respect to time, especially in low-head schemes; therefore, this method requires periodic verification of the hydro-set characteristics. Moreover, the influence of other elements included in the energy conversion system (i.e., electrical generator and power electronic converter) on the total efficiency is significant; thus, an analysis of the power plant should include the entire energy conversion system. This requires conducting identification experiments on a real object. This process is laborious and requires precise measuring devices, which cannot be financially justified in small hydropower plants. To solve this problem, a method dedicated to the identification of the characteristics of an energy conversion system and the optimal operation curve was proposed in [44]. The main advantage of this method is the possibility of carrying out precise identification experiments with limited available measurement points. The identification algorithm is based on artificial intelligence methods, i.e., MLP neural networks, the RBF (radial basis function) method and the SVM (support vector machines) method and dedicated coefficients for approximation assessment. Upon testing this algorithm on real measured data, it was observed that it is possible to limit the number of points by $25 \%$ and maintain the approximation precision of the optimal operation curve.

\subsection{Direct Methods}

The second group of control techniques refers to direct methods based on adaptive algorithms or seeking methods without any prior knowledge of the energy conversion system. 


\subsubsection{MPPT without Hydraulic Parameter Control}

Most of the hydropower control methods described in the literature are concerned with wind and photovoltaic systems, where maximum power point tracking (MPPT) algorithms are generally used. Usually, a non-regulated turbine is analysed without any control over its hydraulic parameters (water head or turbine discharge).

The MPPT technique is based in the well-known perturb and observe (P\&O) method. In this method, the chosen input variable is modified with a small step, and after the plant reaches a steady-state, the variable is adjusted (increased or decreased) depending on the active power change (gradient). The standard P\&O method is easy to implement; however, it is slow, causes oscillation around the MPP and is not resistant to signal noises. The proposed $\mathrm{P} \& \mathrm{O}$ techniques differ in the type of the disturbed variable, for, e.g., DC current [33], generator current [35] and speed [34,36-38,45,46]. An interesting modification in the form of an adaptive perturbation level technique to eliminate oscillations around the MPP was presented in [36]. In [37], the active disturbance rejection technique, which compensates for the influence of internal and external disturbances (flow or torque fluctuations) in the control process, was proposed. All these methods were tested using a hydro-set model based on efficiency Equations (7) and (8). These studies modelled system dynamics using a very low value for the moment of inertia $\left(0.005\right.$ to $\left.0.05 \mathrm{~kg} \cdot \mathrm{m}^{2}\right)$, which is inappropriate for a hydropower scheme. The moment of inertia of an SHP of more than $100 \mathrm{~kW}$ with open channels exceeds $100 \mathrm{~kg} \cdot \mathrm{m}^{2}$.

MPPT can be also realised using an on-line optimization tool, also known as extremum seeking control (ESC). The advantage of this technique over the traditional P\&O method is that it allows a fast convergence to the maximum (extremum) in a time period comparable to the plant dynamics [47]. The usability of ESC in micro-hydropower applications was presented in [48]; the experimental results described the capacity of ESC in noisy and oscillatory conditions.

Previously, several attempts were made to use commercially available photovoltaic inverters with water turbines. In [49], a single-phase inverter was tested in the laboratory with a water turbine model. Dynamic tests indicated a fast inverter response, while the realistic water profile test indicated a high MPPT tracking accuracy of about $96 \%$. In spite of the good steady-state and dynamic results of the presented MPPT, the practical usefulness of this method is limited. The MPPT method without hydraulic parameter control can be justified only for slow non-regulated turbines (the maximum power curve is similar to the optimal operating curve) in the reservoir scheme, where the water level can be controlled by switching the SHP on and off.

\subsubsection{MEPT with Water Level Control}

One of the important tasks of a low-power hydro-set scheme connected to a power system (on-grid) is to improve the economics of the process. Thus, its energy conversion efficiency should be maximised. However, the major task in accomplishing this objective lies in regulating specific hydrological parameters. Most often, this control parameter is the upper water level, which needs to be regulated in the reservoirs of power plants, whereas in run-of-the-river schemes, the upper water limit is set at a constant level. Only a few solutions that include water level control in direct methods that can be applied independent of the turbine type can be found in the available literature. To ensure proper operation of different turbine types, these methods maximise SHP efficiency (thus, they are called maximum efficiency point tracking in short MEPT). One such method was described in [39], where the efficiency of a double-regulated axial tubular turbine was improved using the steepest descent gradient method. The gradient consists of three components corresponding to the control variable (runner blade angle, guide vane angle and speed). Simulation results proved the accuracy of the MEPT algorithm. One of the disadvantages of this method is the significant disturbance experienced by the water level, which can prolong the control speed. The hydraulic system includes long time constants of the water mass in pipelines and water channels (4). Moreover, water-waving phenomena, especially in run-of-the-river schemes, render control over the SHP more difficult. Therefore, SHP control should not cause a significant water flow disturbance. The parameter that influences turbine discharge most 
significantly is usually the guide vane angle (Figure 2). Thus, in practice, it is recommended to use a separate PI regulator with a long integration time as the water level regulator. The second regulator is the generator's load controller for adjusting the hydro-set speed [15]. This controller is influenced by several power plant parameters, namely rotational speed, water head and guide vane angle. In one study [50], a simple gradient method using the objective function of system efficiency was used. The drawback of this method lies in the need for an actual water flow parameter that is necessary for calculating the total energy conversion efficiency. Measuring water flow in low-head schemes is expensive and can be inaccurate in many hydraulic systems, as shown in [51]. Therefore, it is proposed that the water flow parameter be substituted with the actual active power of the hydropower plant. This approach is possible under the assumption of slow variation in water flow in rivers and requires the definition of additional conditions for activating the algorithm, i.e., the limit value of the controller error and time condition. Models developed using the MATLAB/Simulink software confirmed the correct operation of the proposed algorithm under a step input for water flow. Research has demonstrated that this algorithm can adapt to the generator's rotational speed using DC current under time-varying hydrological conditions for maximising system efficiency. A major drawback of this method is the slow speed of the control process and the requirement for a semi-constant water flow, which is difficult to meet in some real-life applications.

\subsection{Hybrid Methods}

As described earlier, direct methods exhibit a key advantage of being adaptable to changes in the system parameters. However, they also suffer from a slow control dynamic that is especially problematic in the case of fast system changes, for, e.g., turn on or modification of system set parameters.

In order to solve this problem, the so-called hybrid method [52] was proposed; it is based on the use of an MLP neural network-type water flow estimator. In this case, an indirect method was used in the supervised learning stage, and a direct method was used in the adaptive module corresponding to the control parameters. Its simple structure and very good approximation features resulted in an estimator based on the MLP network with a relatively low number of neurons in the hidden layer (three neurons) due to the high measurement uncertainty in the analysed parameters. The load regulator of the generator was based on a simple gradient method using the objective function of system efficiency. In order to improve the dynamic characteristics of the algorithm, the optimal curve of the generator load modified during algorithm operation for meeting specific conditions was used. This solution eliminated the basic disadvantages of the direct method (low control dynamics) and the indirect method (no adaptation to actual conditions). The main disadvantage of hybrid methods lies in their complexity and need for parameter tuning for a given SHP.

A review of the proposed control methods and analysis of their features lead to the following conclusions:

- A hydropower plant model should include the static and dynamic features of the turbine and hydraulic system (in case of long penstocks that provide water to the turbine or surge tank presence).

- An analytical model of the hydro-set (used in indirect methods) should be based on polynomial equations related to turbine discharge and efficiency (approximated by neural networks for example).

- The turbine type (slow, normal and fast) and SHP function (run-of-the-river and reservoir) determine the control objective (control curve).

- The control algorithm should include the influence of the generator and PEC efficiency on the optimal operating curve (the total efficiency or output power needs to be analysed).

- Maximisation of the SHP output power (pure MPPT) is justified only for non-regulated slow turbines in the reservoir scheme, where the water level can be controlled by switching the SHP on and off. 
- The control algorithm must include hydraulic parameter regulation (e.g., water level), which may influence the control technique significantly.

- Adjustment of the system parameters that influence turbine discharge (usually the guide vane angle) needs to be minimised in order to prevent hydraulic system disturbance.

- Measurement of turbine discharge (necessary in the MEPT algorithm) in the low-head scheme needs to be reduced (for example, by using a discharge estimator).

The control techniques presented in this section are compared in Table 1 taking into account their control features and applicability.

Table 1. A comparison of the control methods for SHPs with variable speed operation.

\begin{tabular}{|c|c|c|c|c|c|c|}
\hline \multirow[t]{2}{*}{ Control Method } & \multicolumn{3}{|c|}{ Indirect } & \multicolumn{2}{|l|}{ Direct } & \multirow[b]{2}{*}{$\begin{array}{l}\text { Hybrid } \\
\text { [52] }\end{array}$} \\
\hline & $\begin{array}{c}\text { Analytical } \\
\text { [25-38] }\end{array}$ & $\begin{array}{c}\text { Look-Up } \\
\text { Table } \\
{[39-41]}\end{array}$ & $\begin{array}{c}\text { Hill } \\
\text { Diagram } \\
{[42,43]}\end{array}$ & $\begin{array}{c}\text { MPPT } \\
{[33-38,45-49,53]}\end{array}$ & $\begin{array}{l}\text { MEPT } \\
{[39,50]}\end{array}$ & \\
\hline \multicolumn{7}{|l|}{ Control } \\
\hline Dynamic & +++ & +++ & +++ & ++ & + & +++ \\
\hline Algorithm simplicity & +++ & ++ & ++ & ++ & + & + \\
\hline Adaptation & + & + & + & +++ & +++ & +++ \\
\hline \multicolumn{7}{|l|}{ Applicability } \\
\hline Non-regulated turbine & +++ & +++ & +++ & ++ & +++ & +++ \\
\hline Single-regulated turbine & ++ & ++ & ++ & - & ++ & ++ \\
\hline Run-of-the-river & ++ & ++ & ++ & - & ++ & ++ \\
\hline Reservoir & +++ & ++ & ++ & ++ & +++ & +++ \\
\hline
\end{tabular}

\section{Methodology of Optimal Operating Curve Determination}

The control methods described above show that the determination of the optimal control curve is troublesome due to the static and dynamic features of the hydraulic system, which depend on many parameters and may change during operation. The commonly used empirical formulas presented above apply only to specific unregulated turbines; hence the need for a formula that determines the optimal operating curve for different types of turbines based on the basic dimensions of the turbine.

The optimal operating speed can be calculated from the geometrical dimensions of the turbine. The velocity vectors of the water flowing through the turbine are usually expressed in cylindrical coordinates [22]. For axial-flow machines where the direction of rotation is perpendicular to the fluid flow, the radial component is ignored. Figure 4 shows the vectors of velocity in the turbine blade and guide vanes.

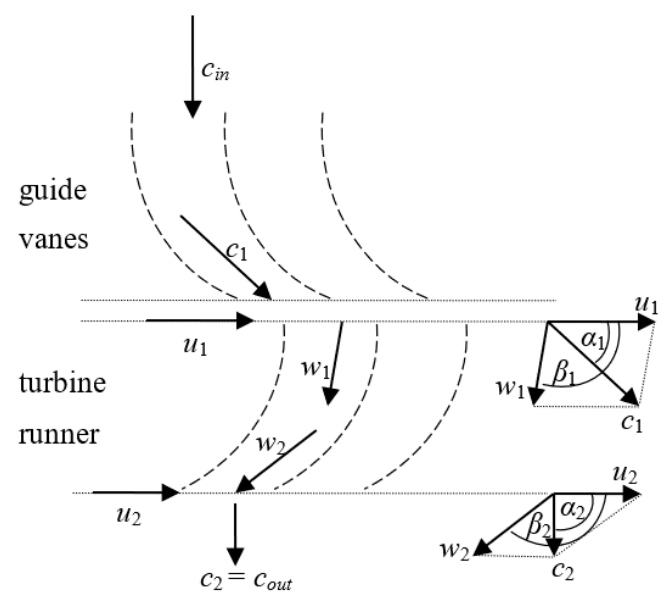

Figure 4. A velocity diagram of an axial-turbine. 
The absolute water velocity $c$ is the sum of the relative velocity $w$ and the tangential velocity of the runner $u$. The absolute water velocity at the outlet of the guide vanes is $c_{1}$ at the angle $\alpha_{1}$ (guide vane outlet angle), which is equal to the relative velocity $w_{1}$ of the inlet guide at the angle $\beta_{1}$ (runner inlet angle). The velocity of the water varies in the runner, creating a torque, and exits it at a relative velocity $w_{2}$ at an angle $\beta_{2}$ (runner outlet angle), which is equal to the absolute velocity at the turbine outlet $c_{2}=c_{\text {out }}$ at an angle $\alpha_{2}$ (turbine outlet angle). In principle, Bernoulli's formula for a steady-state water turbine for an incompressible flow can be expressed as Equation (10) [22].

$$
\frac{\Delta c^{2}+\Delta w^{2}+\Delta u^{2}}{2 g}=H+\frac{c_{i n}^{2}-c_{o u t}^{2}}{2 g}-\sum H_{l o s s}
$$

where $\Delta x^{2}=x_{1}^{2}-x_{2}^{2}$ in $(\mathrm{m} / \mathrm{s})$ is the gradient of the square water velocity (c-absolute velocity, $w$-relative velocity, $u$-tangential runner velocity), $c_{\text {in }}\left(c_{\text {out }}\right)$ is the turbine input (output) velocity, $g\left(9.81 \mathrm{~m} / \mathrm{s}^{2}\right)$ is gravitational acceleration, and $H_{\text {loss }}$ in $(\mathrm{m})$ is the water flow losses expressed in head losses.

The turbine equation allows the definition the turbine torque formula (called also the Euler turbine equation):

$$
T=\frac{\gamma \cdot Q}{g}\left(R_{1} c_{1} \cos \alpha_{1}-R_{2} c_{2} \cos \alpha_{2}\right)
$$

where $\gamma\left(\mathrm{N} / \mathrm{m}^{3}\right)$ is the specific weight of water, $R_{1}(\mathrm{~m})$ is the outside radius and $R_{2}(\mathrm{~m})$ is the inside radius of the runner.

To reduce water turbulence due to the instantaneous change in water direction, the relative velocity vector must be tangent to the surface of the inlet runner. The second rule of proper turbine design is that the water exiting the runner is axial with the outlet pipe $\left(\alpha_{2}=90^{\circ}\right)$. These conditions ensure the lowest hydraulic losses and thus the highest efficiency. Taking these assumptions into account, the formula for the optimal speed Equation (12) can be obtained from Equation (11).

$$
n_{\text {opt }}=\frac{30}{\pi R_{1}} \sqrt{\eta g H} \sqrt{1-\frac{\tan \alpha_{1}}{\tan \beta_{1}}}
$$

where $R_{1}(\mathrm{~m})$ is the runner outside radius, $\eta$ is the turbine efficiency, $g\left(9.81 \mathrm{~m} / \mathrm{s}^{2}\right)$ is gravitational acceleration, $H(\mathrm{~m})$ is the water head, $\alpha_{1}$ is the guide vane outlet angle and $\beta_{1}$ is the rotor inlet angle.

The presented formula is simplified because it does not take into account the changes in shape along the radius of the turbine runner. In addition, it ignores the influence of the generator and PEC on the optimal speed curve. However, it can be used to determine the initial optimal operating curve in both the indirect and direct methodology.

The greatest inaccuracy of the presented Formula (12) results from the neglect of changes in efficiency at different guide vane angles. In order to improve the calculation results, the efficiency function can be implemented. The previously described formulas (e.g., Formula (9)) require detailed system parameters. Therefore, it is proposed to simplify this formula using the parabola function Equation (13) with the vertex as the nominal operating point of the turbine $\left(\eta_{\mathrm{N}}, \alpha_{\mathrm{N}}\right)$. The second operating point $\left(\eta_{\mathrm{x}}, \alpha_{\mathrm{x}}\right)$ necessary to formulate the efficiency function can be estimated or measured.

$$
\eta\left(\alpha_{1}\right)=\frac{\eta_{x}-\eta_{N}}{\left(\alpha_{x}-\alpha_{N}\right)^{2}}\left(\alpha_{1}-\alpha_{N}\right)^{2}+\eta_{N}
$$

\section{Case Study}

The formula determining the optimal operating curve on the basis of the basic dimensions of the turbine (12) was verified on the example of an experimental SHP with a power of $150 \mathrm{~kW}$, which combines two hydro-sets presented earlier in [15]. The hydro-set consists of a propeller turbine and a permanent magnet synchronous generator (PMSG). The propeller turbine is integrated with the 
PMSG and coupled to the power grid through a full-sized AC/AC converter (Figure 5). The converter contains a diode rectifier bridge with a DC/DC boost converter and a direct power control space-vector modulation (DPC-SVM) controlled two-level converter on the grid side. The control algorithm (Figure 6) consists of two separate controllers: a water level regulator and a load regulator. The first one gives a constant value of the water level in the inlet channel, which is required in the run-of-the-river power plant. A PI controller with a long integral time is used. The load controller regulates the torque or power of the generator in order to obtain the given turbine speed.

The discharge of the turbine is regulated by guide vanes with a nominal position of $53^{\circ}$. The nominal head $H_{N}$ of the SHP is $3.5 \mathrm{~m}$, and the nominal discharge $Q_{N}$ is $3 \mathrm{~m}^{3} \mathrm{~s}^{-1}$. The inlet angle of the runner differs on the radius due to the twist of the blade (Figure 7); therefore, the average value of the inlet and outlet angle $\left(\beta_{1}=148^{\circ}\right)$ and the guide radius $\left(R_{1}=0.3325 \mathrm{~m}\right)$ are assumed. The efficiency of the hydro-set is $75 \%$. The outlet angle of the guide vanes $\alpha_{1}$ is a variable of the optimal speed function (12). The comparison of the optimal operating curve calculated using the formula (12) (solid black line) and the measured curve (blue crosses) on the SHP [15] is shown in Figure 8. The optimal operating speed for a given angle of the guide vanes differs especially for a low value of this angle. This discrepancy is due to the assumption that the efficiency is constant when the guide vanes are changed and can cause significant losses in the efficiency of the hydro-set. Nevertheless, Formula (12) can be directly used as the initial optimal operating curve.

In order to improve the accuracy of the curve, an efficiency function (13) approximated by a parabola can be introduced. The nominal operating point $(0.75,53)$ and the measurement point $(0.55,17)$ are taken, and the resulting efficiency function is shown in Figure 9. The optimal operating curve corrected by the efficiency function is shown in Figure 8 (green dashed line).

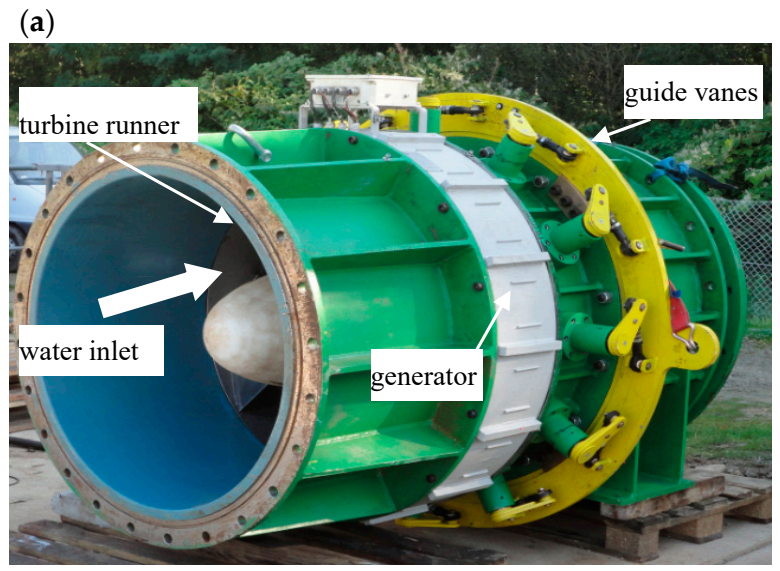

(b)

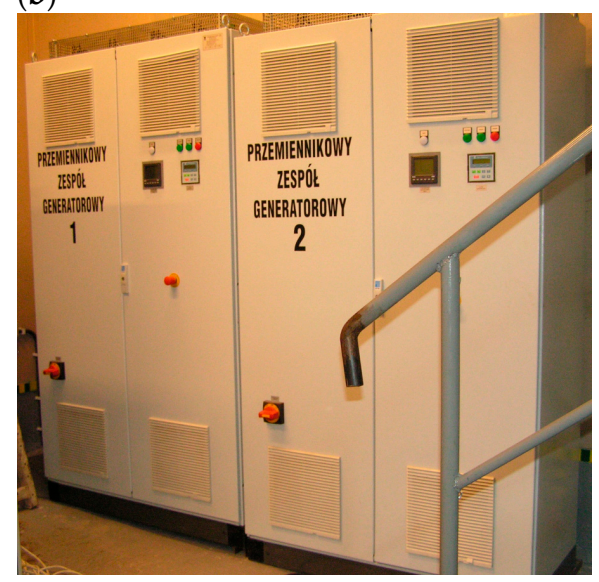

(c)

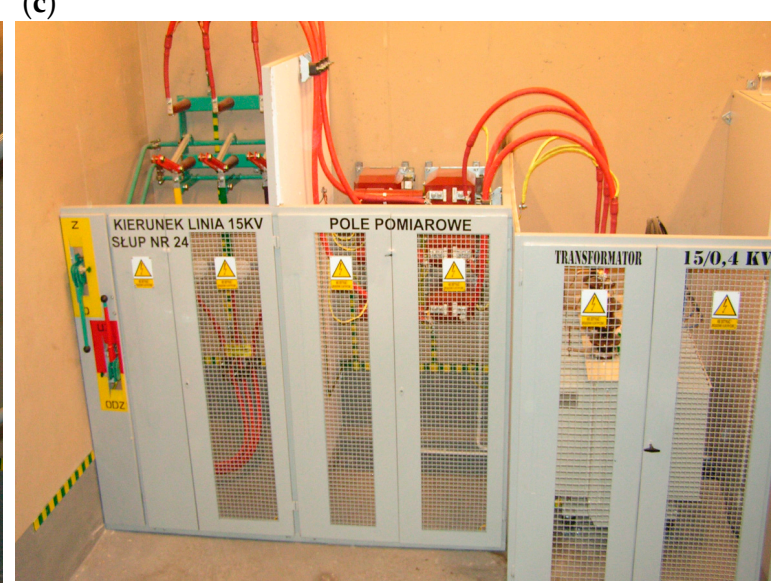

Figure 5. The experimental SHP: (a) hydro-set of $75 \mathrm{~kW}$, (b) two power electronic converters (PECs) of $90 \mathrm{~kW}$ and (c) grid connection devices. 


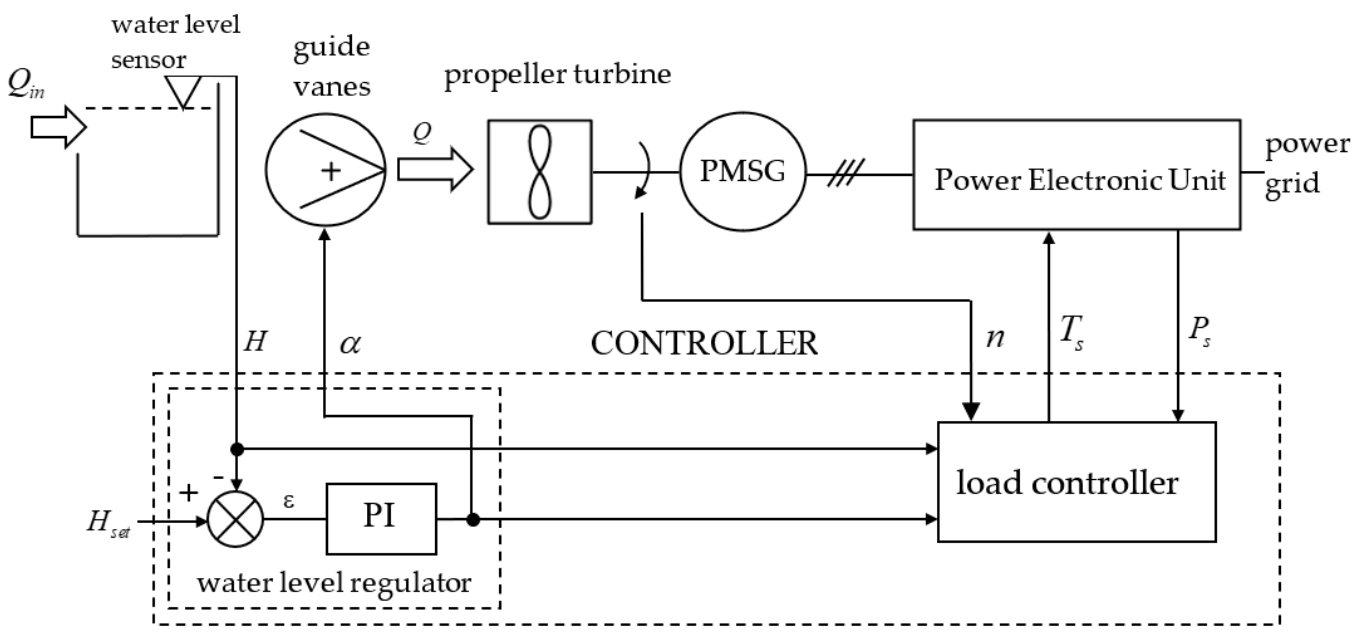

Figure 6. Algorithm for controlling a single hydro-set.

(b)
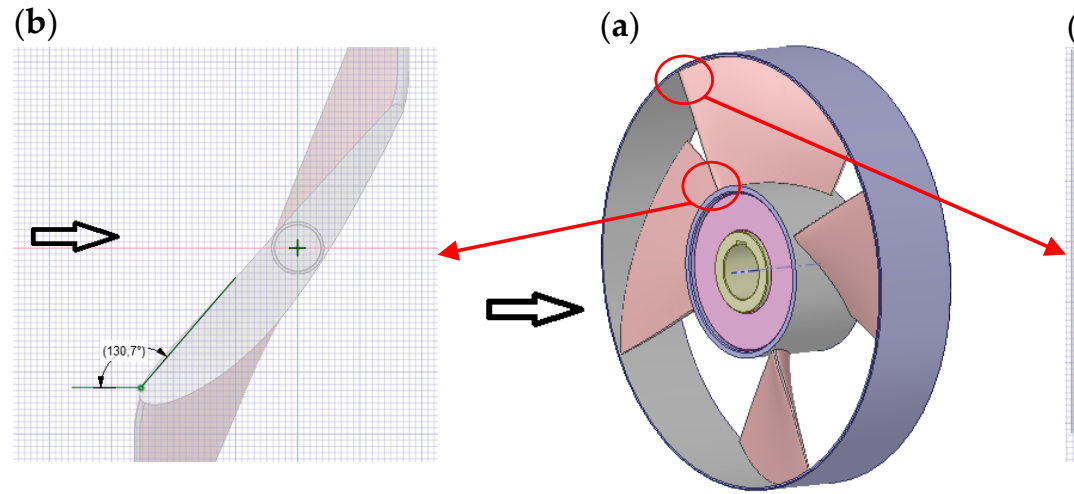

(c)

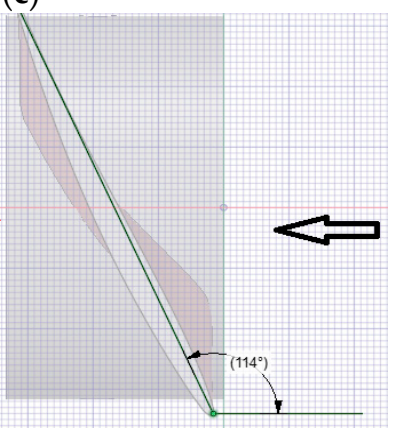

Figure 7. Turbine runner geometry (a) with inlet angles: inside angle (b) and outside angle (c).

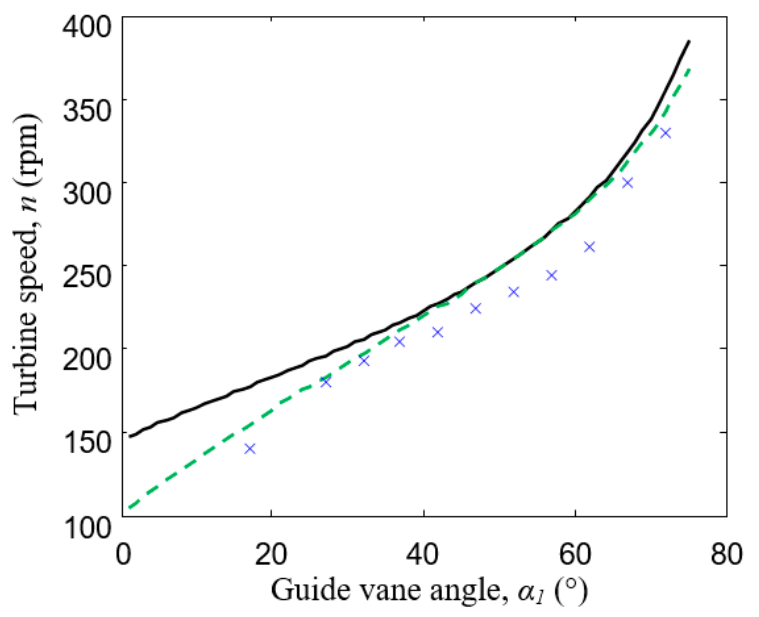

Figure 8. Optimal operation speed curve calculated (solid line-Formula (12), dashed line-Formulas (12) and (13)) and measured (crosses). 


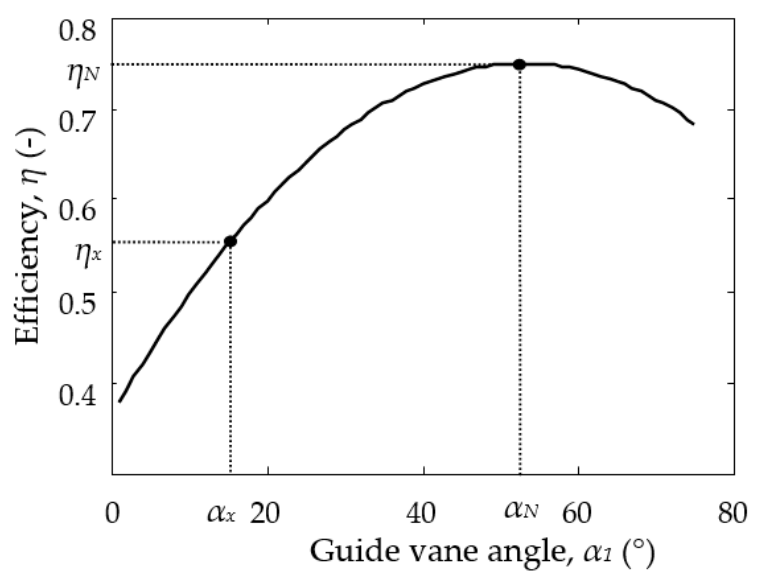

Figure 9. Efficiency function estimated by the parabola function.

The optimal operating curves, measured and calculated with simplified and corrected formulas, are also compared in the hill chart (Figure 10). Additionally, a constant speed curve is also given. From the point of view of profitability, efficiency as a function of turbine discharge is of particular interest (Figure 11). The loss of efficiency is most significant at a constant operating speed, which is especially characteristic of a fast turbine.

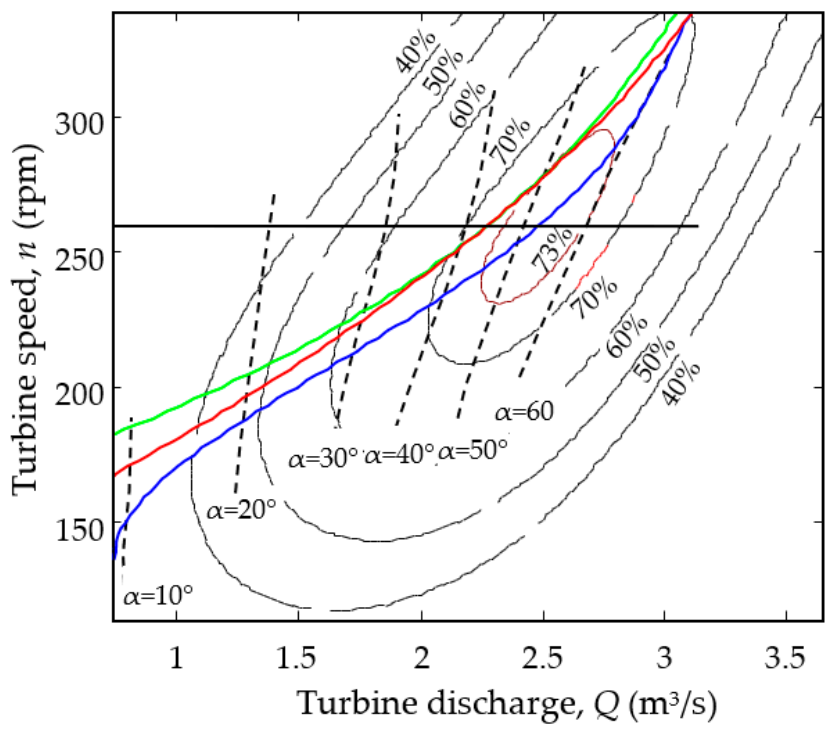

Figure 10. Hill charts of an experimental turbine showing the optimal measured operating curve (solid blue line), calculated performance curve using the simplified formula (solid green line), revised formula (solid red line) and constant speed curve (solid black line).

In order to show the differences in the efficiency curves, the efficiency loss parameter $\Delta \eta$ was introduced. It is calculated by subtracting the efficiency obtained for the variable speed (calculated) or constant speed operating curve from the optimal variable speed operating curve. The values of efficiency losses as a function of turbine discharge are shown in Figure 12. The average values of efficiency losses in the scope of turbine operation $\left(0.75-3.1 \mathrm{~m}^{3} / \mathrm{s}\right)$ are: $1 \%$ for variable speed with a simplified formula $\left(\Delta \eta_{v s_{\_} s}\right), 0.6 \%$ for variable speed with corrected formula $\left(\Delta \eta_{v s_{-} c}\right)$ and $10 \%$ for constant speed operation $\left(\Delta \eta_{c s}\right)$. 


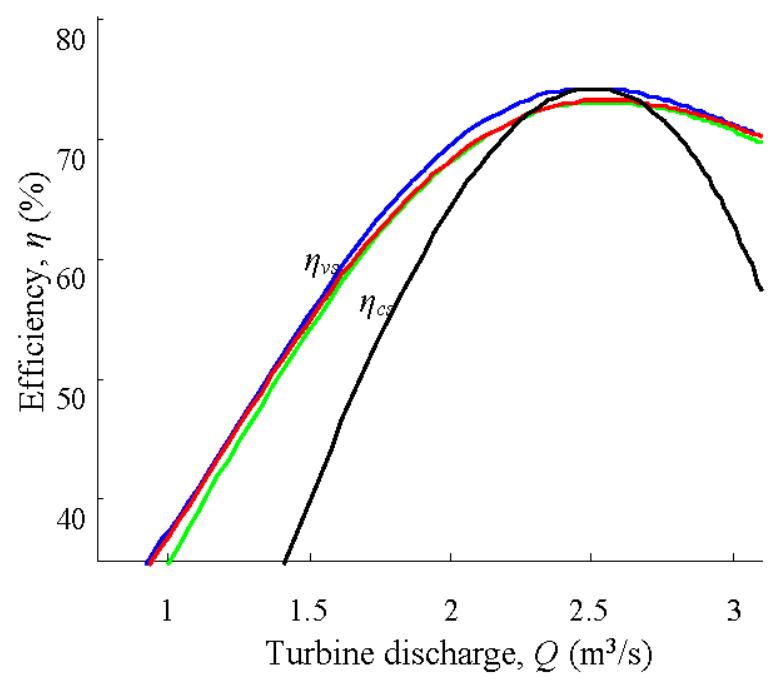

Figure 11. Turbine efficiency as a function of turbine discharge for the optimal measured operation curve (solid blue line), operation curves defined by the simplified formula (solid green line), corrected formula (solid red line) and constant speed operating curve (solid black line).

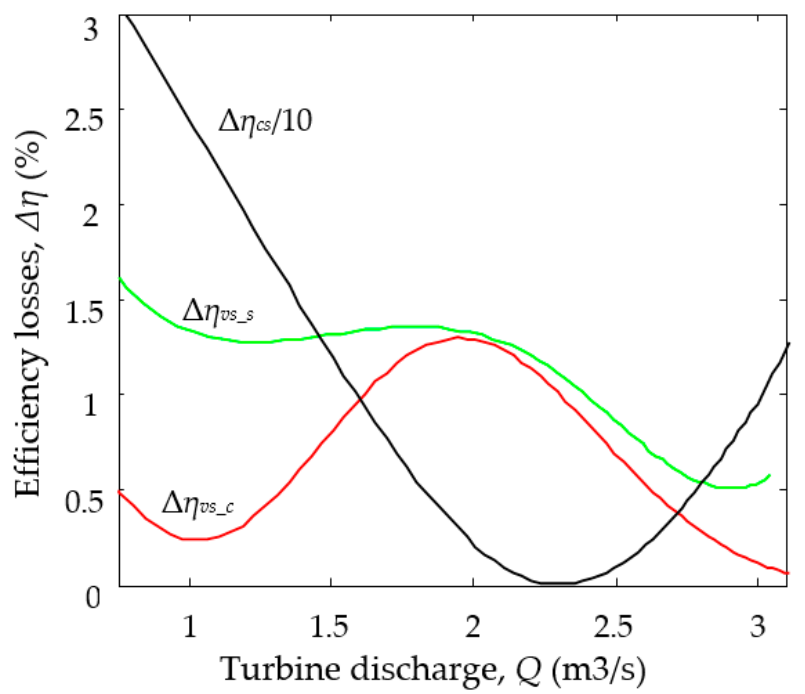

Figure 12. Turbine efficiency losses as a function of discharge for the simplified formula (solid green line), the corrected formula (solid red line) and the constant speed curve (solid black line) divided by 10 .

The energy produced is strongly dependent on the flow duration curve (FDC) of a given point in the river, which shows the proportion of the time for which the flow is equal to or exceeds certain values (Figure 13). Moreover, the useful flow of the river $Q_{u}$ is limited by the maximum and minimum turbine discharge. The output power is also influenced by changes in head as a function of river flow $H(Q)$. The head can change significantly, especially in low head installations where the water flow above the rated value increases the water level at both the inlet and the tailrace, but at a different rate. Assuming the turbine discharge efficiency function $\eta(Q)$ presented in Figure 11, the output power can be calculated from the formula:

$$
P=9.81 \cdot Q_{u} \cdot H(Q) \cdot \eta(Q)
$$

The efficiency of the turbine at variable speed is quite stable, and the power corresponds to the discharge profile. However, at constant speed, the efficiency varies significantly with the turbine flow rate (e.g., a difference of $0.5 \mathrm{~m}^{3} / \mathrm{s}$ from the nominal value results in an $11 \%$ decrease in efficiency) (see Figure 12). This situation is visible around Day 100, where the efficiency of the turbine is 
$62 \%\left(Q=3 \mathrm{~m}^{3} / \mathrm{s}\right)$, while on Day 120 , it increases the efficiency to $74 \%$ due to the nominal discharge of the turbine $\left(Q=2.5 \mathrm{~m}^{3} / \mathrm{s}\right)$. This results in a power difference of $10 \%$ taking into account the discharge change.

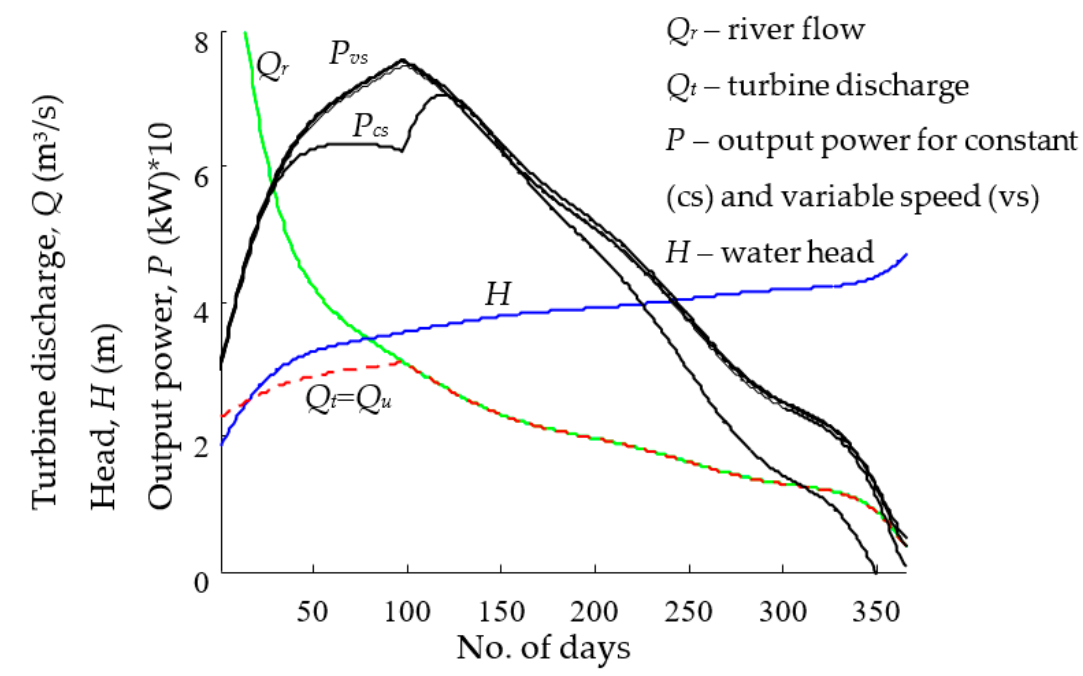

Figure 13. Annual performance curves: river flow $\left(Q_{\mathrm{r}}\right)$, turbine discharge $\left(Q_{\mathrm{t}}\right)$, output power for constant $\left(P_{\mathrm{cs}}\right)$ and variable speed $\left(P_{\mathrm{vs}}\right)$.

Based on the annual production curves shown in Figure 13, the energy production can be calculated (Table 2).

Table 2. Annual energy production comparison.

\begin{tabular}{|c|c|c|}
\hline & Annual Energy Production $E(\mathbf{k W h})$ & Annual Energy Ratio \\
\hline Optimal operation curve & $E_{\text {Vs_opt }}=419,560$ & 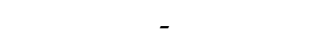 \\
\hline Simplified Formula (12) & $E_{\mathrm{VS} \_\mathrm{s}}=411,760$ & $E_{\mathrm{Vs} \_\mathrm{s}} / E_{\mathrm{Vs} \_\mathrm{opt}}=0.981$ \\
\hline Corrected Formulas (12) and (13) & $E_{\mathrm{Vs} \_\mathrm{p}}=415,140$ & $E_{\mathrm{Vs} \_\mathrm{p}} / E_{\mathrm{Vs} \_\mathrm{opt}}=0.989$ \\
\hline Constant speed operation & $E_{\mathrm{cs}}^{-1}=363,630$ & $E_{\mathrm{cs}} / E_{\mathrm{vs} \_ \text {opt }}=0.867$ \\
\hline
\end{tabular}

As a result, the energy production in variable speed operation with the optimal measurement curve is $419,560 \mathrm{kWh}$, while the simplified formula gives $1.9 \%$ energy loss. The proposed correction (13) of Formula (12) reduces the losses to $1.1 \%$. On the other hand, losses during operation at constant speed are $13.3 \%$. The presented results confirmed the effectiveness of the universal simplified formula for the identification of the optimal SHP operating curve with variable speed.

To achieve variable speed operation, a power electronic converter (PEC) is needed. The average cost of a PEC, depending on functionality and supplier, ranges from $\$ 200 / \mathrm{kW}$ to $\$ 250 / \mathrm{kW}$. The cost-effectiveness of using variable speed depends on the system solution (turbine and generator type) and can be analysed considering two options. The first is the application of variable speed operation to an existing propeller turbine presented in the article. Here, the return on investment, assuming a profit on sales of energy at the level of $100 \$ / \mathrm{MWh}$, will be achieved after seven years. The second case is the possibility of using a variable speed propeller turbine instead of the more expensive (approximately 30\%) standard double-regulated Kaplan turbine. Considering a Kaplan turbine cost of $\$ 1300 / \mathrm{kW}$, the cost of a $150 \mathrm{~kW}$ system (propeller turbine and PEC) will be approximately $10 \%$ lower while maintaining similar energy production. 


\section{Conclusions}

The presented analysis shows that control over small hydropower plants with variable speed operation is troublesome, especially in the low-head scheme, where the dynamics of the hydraulic system influences system control significantly and the measurement of turbine discharge is difficult. Moreover, turbine type has a significant effect on the SHP steady-state. The presented examples of hill diagrams show that the selection of the objective control function (control curve) affects energy production results.

The control methods analysis leads to a recommendation that indirect methods should be used to define the initial operation curve due to their simplicity and high dynamics. Further, the operation curve should be periodically adapted to the actual system features using direct control techniques. This approach, which is termed the hybrid method, seems to be the most promising for controlling SHPs working at variable speed. The main disadvantages of hybrid methods lie in their algorithm complexity and algorithm parameter adjustment for a given SHP.

In order to simplify the determination of the optimal operating curve, the article proposes the use of an analytical formula based on the geometrical dimensions of the turbine. The verification of this formula with actual measurements showed that it can be used to identify the initial performance curve in hybrid methods. The inaccuracies of the results can be reduced by implementing an efficiency function in the form of a parabola function that is calculated using only two operating points, including the nominal point. This improvement makes the operation curve precise enough that it can be used as an optimal solution in indirect methods. As shown on the example of the real SHP, the proposed method provides only $1 \%$ production losses compared to the optimal operating curve.

The second aspect of the work is to compare the operation with constant and variable rotational speed in a small hydropower plant. The results of the analysis of efficiency and annual energy production showed the advantage of variable speed, which is particularly important in the case of a propeller turbine, where the annual energy production increased by almost $16 \%$. The energy gain using this technique is much less with a slow turbine, such as a Francis turbine, and its profitability is questionable. In addition, the presence of PECs in the energy conversion chain reduces overall system efficiency. On the other hand, PEC minimizes the negative impact of the power plant on the power system by controlling the power factor, improves system flexibility and facilitates integration with photovoltaic, wind and battery systems, creating a hybrid power micro-grid.

Author Contributions: Conceptualization, D.B.; methodology, D.B. and M.M.; software, D.B.; validation, M.M.; formal analysis, D.B. and M.M.; investigation, D.B.; resources, D.B. and M.M.; data curation, D.B.; writing-original draft preparation, D.B.; writing-review and editing, M.M.; visualization, D.B.; supervision, D.B. All authors have read and agreed to the published version of the manuscript.

Funding: This work was supported by funds for statutory activity from the Cracow University of Technology (No. E-2/568/2018/DS) under the subsidies on science granted by the Polish Ministry of Science and Higher Education.

Conflicts of Interest: The authors declare no conflict of interest.

\section{References}

1. REN21. Renewables 2018 Global Status Report. Available online: http://www.ren21.net/wp-content/uploads/ 2018/06/17-8652_GSR2018_FullReport_web_final_.pdf (accessed on 22 January 2019).

2. $\mathrm{Xu}, \mathrm{J} . ; \mathrm{Ni}, \mathrm{T}$; Z Zheng, B. Hydropower development trends from a technological paradigm perspective. Energy Convers. Manag. 2015, 90, 195-206. [CrossRef]

3. Sachdev, H.S.; Akella, A.K.; Kumar, N. Analysis and evaluation of small hydropower plants: A bibliographical survey. Renew. Sustain. Energy Rev. 2015, 51, 1013-1022. [CrossRef]

4. Manzano-Agugliaro, F.; Taher, M.; Zapata-Sierra, A.; Juaidi, A.; Montoya, F.G. An overview of research and energy evolution for small hydropower in Europe. Renew. Sustain. Energy Rev. 2017, 75, 476-489. [CrossRef]

5. Yildiz, V.; Vrugt, J.A. A toolbox for the optimal design of run-of-river hydropower plants. Environ. Model. Softw. 2019, 111, 134-152. [CrossRef] 
6. Blaabjerg, F.; Yang, Y.; Yang, D.; Wang, X. Distributed Power-Generation Systems and Protection. Proc. IEEE 2017, 105, 1311-1331. [CrossRef]

7. Elliott, D. A balancing act for renewables. Nat. Energy 2016, 1, 15003. [CrossRef]

8. Ardizzon, G.; Cavazzini, G.; Pavesi, G. A new generation of small hydro and pumped hydro power plants: Advances and future challenges. Renew. Sustain. Energy Rev. 2014, 31, 746-761. [CrossRef]

9. Yang, W.; Yang, J. Advantage of variable-speed pumped storage plants for mitigating wind power variations: Integrated modelling and performance assessment. Appl. Energy 2019, 237, 720-732. [CrossRef]

10. Nababan, S.; Muljadi, E.; Blaabjerg, F. An overview of power topologies for micro-hydro turbines. In Proceedings of the 3rd International Symposium on Power Electronics for Distributed Generation Systems, Aalborg, Denmark, 25-26 June 2012; pp. 737-744.

11. Iliev, I.; Trivedi, C.; Dahlhaug, O.G. 'Variable-speed operation of Francis turbines: A review of the perspectives and challenges'. Renew. Sustain. Energy Rev. 2019, 103, 109-121. [CrossRef]

12. Fraile-Ardanuy, J.; Wilhelmi, J.R.; Fraile-Mora, J.J.; Pérez, J.I. Variable-Speed hydro generation: Operational aspects and control. IEEE Trans. Energy Convers. 2006, 21, 569-574. [CrossRef]

13. Valavi, M.; Nysveen, A. Variable-Speed Operation of Hydropower Plants: A Look at the Past, Present, and Future. IEEE Ind. Appl. Mag. 2018, 24, 18-27. [CrossRef]

14. Kroposki, B.; Pink, C.; DeBlasio, R.; Thomas, H.; Simões, M.; Sen, P.K. Benefits of Power Electronic Interfaces for Distributed Energy Systems. IEEE Trans. Energy Convers. 2010, 25, 901-908. [CrossRef]

15. Borkowski, D.; Wegiel, T. Small Hydropower Plant with Integrated Turbine-Generators Working at Variable Speed. IEEE Trans. Energy Convers. 2013, 28, 452-459. [CrossRef]

16. Fang, H.; Chen, L.; Dlakavu, N.; Shen, Z. Basic Modeling and Simulation Tool for Analysis of Hydraulic Transients in Hydroelectric Power Plants. IEEE Trans. Energy Convers. 2008, 23, 834-841. [CrossRef]

17. Working Group on Prime Mover and Energy Supply Models for System Dynamic Performance Studies. Hydraulic turbine and turbine control models for system dynamic studies. IEEE Trans. Power Syst. 1992, 7, 167-179. [CrossRef]

18. An, X.; Pan, L.; Yang, L. Condition parameter degradation assessment and prediction for hydropower units using Shepard surface and ITD. Trans. Inst. Meas. Control 2014, 36, 1074-1082. [CrossRef]

19. Iman-Eini, H.; Frey, D.; Bacha, S.; Boudinet, C.; Schanen, J. Evaluation of loss effect on optimum operation of variable speed micro-hydropower energy conversion systems. Renew. Energy 2019, 131, 1022-1034. [CrossRef]

20. Borkowski, D. Analytical Model of Small Hydropower Plant Working at Variable Speed. IEEE Trans. Energy Convers. 2018, 33, 1886-1894. [CrossRef]

21. Sayers, A.T. Hydraulic and Compressible Flow Turbomachines; Mcgraw-Hill: Berkshire, UK, 1990.

22. Dixon, S.L.; Hall, C.A. Fluid Mechanics and Thermodynamics of Turbomachinery; Elsevier: Amsterdam, The Netherlands, 2010.

23. White, F.M. Fluid Mechanic, 7th ed.; McGraw-Hill: New York, NY, USA, 2011.

24. Yang, W.; Yang, J.; Guo, W.; Norrlund, P. Frequency stability of isolated hydropower plant with surge tank under different turbine control modes. Electr. Power Compon. Syst. 2015, 43, 1707-1716. [CrossRef]

25. Muljadi, E.; Singh, M.; Gevorgian, V.; Mohanpurkar, M.; Hovsapian, R.; Koritarov, V. Dynamic modeling of adjustable-speed pumped storage hydropower plant. In Proceedings of the IEEE Power \& Energy Society General Meeting, Denver, CO, USA, 26-30 July 2015; pp. 1-5. [CrossRef]

26. Gao, H.; Wang, C. Effect of Detailed Hydro Turbine Models on Power System Analysis. In Proceedings of the IEEE PES Power Systems Conference and Exposition, Atlanta, GA, USA, 29 October-1 November 2006; pp. 1577-1581. [CrossRef]

27. Huimin, G.; Xianlin, L. Transient simulation of hydroelectric system based on hydro-mechanical-electro detailed model. J. Syst. Simulata 2003, 15, 469-471.

28. Vereide, K.; Lia, L.; Nielsen, T.K. Hydraulic scale modelling and thermodynamics of mass oscillations in closed surge tanks. J. Hydraul. Res. 2015, 53, 519-524. [CrossRef]

29. Gil-González, W.; Garcés, A.; Fosso, O.B. Passivity-Based Control for Small Hydro-Power Generation with PMSG and VSC. IEEE Access 2020, 8, 153001-153010. [CrossRef]

30. Bidgoli, M.A.; Yang, W.; Ahmadian, A. DFIM versus synchronous machine for variable speed pumped storage hydropower plants: A comparative evaluation of technical performance. Renew. Energy 2020, 159, 72-86. [CrossRef] 
31. Dong, Z.; Tan, J.; Muljadi, E.; Nelms, R.M.; St-Hilaire, A.; Pevarnik, M.; Jacobson, M.D. Developing of Quaternary Pumped Storage Hydropower for Dynamic Studies. IEEE Trans. Sustain. Energy 2020, 11, 2870-2878. [CrossRef]

32. De Mesquita, L.M.O.; Dos Santos Menas, J.; van Emmenk, E.L.; Aredes, M. Maximum power point tracking applied on small hydroelectric power plants. In Proceedings of the 2011 International Conference on Electrical Machines and Systems, Beijing, China, 20-29 August 2011; pp. 1-6.

33. Márquez, J.L.; Molina, M.G.; Pacas, J.M. Dynamic modeling, simulation and control design of an advanced micro-hydro power plant for distributed generation applications. Int. J. Hydrogen Energy 2010, 35, 5772-5777. [CrossRef]

34. Belhadji, L.; Bacha, S.; Roye, D. Modeling and control of variable speed micro-hydropower plant based on Axial-flow turbine and permanent magnet synchronous generator (MHPP-PMSG). In Proceedings of the 37th Annual Conference of the IEEE Industrial Electronics Society, Melbourne, Australia, 7-10 November 2011; pp. 896-901.

35. Belhadji, L.; Bacha, S.; Roye, D.; Rekioua, T. Experimental validation of direct power control of variable speed micro-hydropower plant. In Proceedings of the IECON 2012-38th Annual Conference on IEEE Industrial Electronics Society, Montreal, QC, USA, 25-28 October 2012; pp. 995-1000. [CrossRef]

36. Belhadji, L.; Bacha, S.; Munteanu, I.; Rumeau, A.; Roye, D. Adaptive MPPT Applied to Variable-Speed Microhydropower Plant. IEEE Trans. Energy Convers. 2013, 28, 34-43. [CrossRef]

37. Guo, B.; Bacha, S.; Alamir, M.; Imanein, H. An anti-disturbance ADRC based MPPT for variable speed micro-hydropower plant. In Proceedings of the IECON 2017-43rd Annual Conference of the IEEE Industrial Electronics Society, Beijing, China, 29 October-1 November 2017; pp. 1783-1789. [CrossRef]

38. Zhang, J.; Leontidis, V.; Dazin, A.; Tounzi, A.; Delarue, P.; Caignaert, G.; Piriou, F.; Libaux, A. Canal lock variable speed hydropower turbine design and control. IET Renew. Power Gener. 2018, 12, 1698-1707. [CrossRef]

39. Borghetti, A.; Di Silvestro, M.; Naldi, G.; Paolone, M.; Alberti, M. Maximum efficiency point tracking for adjustable-speed small hydropower plant. In Proceedings of the 16th Power Systems Computation Conference, Glasgow, UK, 14-18 July 2008; pp. 1-7.

40. Brezovec, M.; Kuzle, I.; Tomisa, T. Nonlinear digital simulation model of hydroelectric power unit with Kaplan turbine. IEEE Trans. Energy Convers. 2006, 21, 235-241. [CrossRef]

41. Perez-Diaz, J.I.; Fraile-Ardanuy, J. Neural networks for optimal operation of a run-of-river adjustable speed hydro power plant with axialflow propeller turbine. In Proceedings of the 16th Mediterranean Conference Control Automation, Ajaccio, France, 25-27 June 2008; pp. 309-314.

42. Tessarolo, A.; Luise, F.; Raffin, P.; Degano, M. Traditional hydropower plant revamping based on a variable-speed surface permanent-magnet hightorque- density generator. In Proceedings of the 2011 International Conference on Clean Electrical Power, Ischia, Italy, 2-4 July 2011; pp. 350-356.

43. Fraile-Ardanuy, J.J.; Pérez, J.I.; Sarasúa, I.; Wilhelmi, J.R.; Fraile-Mora, J. Speed control of run-of-river variable speed hydro plants. In Proceedings of the 2006 International Conference on Renewable Energy and Power Quality, Madrid, Spain, 5 April-5 June 2006; pp. 182-187.

44. Borkowski, D. Identification of the Optimal Control Characteristics of a Small Hydropower Plant Using Artificial Neural Networks and the Support Vector Machines Method. J. Hydraul. Res. 2019, 57, 715-723. [CrossRef]

45. Krishnakumar, V.R.; Ramachandaramurthy, K.V.; Gomathi, V.; Ekanayake, J.B.; Tiong, S.K. Modelling and simulation of variable speed pico hydel energy storage system for microgrid applications. J. Energy Storage 2019, 24, 100808. [CrossRef]

46. Michas, M.; Ugalde-Loo, C.E.; Ming, W.; Jenkins, N.; Runge, S. Maximum power extraction from a hydrokinetic energy conversion system. IET Renew. Power Gener. 2019, 13, 1411-1419. [CrossRef]

47. Ariyur, K.; Krstic, M. Real-Time Optimization by Extremum-Seeking Control; Wiley-Interscience: Hoboken, NJ, USA, 2003.

48. Atta, K.T.; Johansson, A.; Cervantes, M.J.; Gustafsson, T. Maximum power point tracking for micro hydro power plants using extremum seeking control. In Proceedings of the 2015 IEEE Conference on Control Application, (CCA), Sydney, Australia, 21-23 September 2015; pp. 1874-1879. [CrossRef]

49. Borkowski, D. Performance analysis of the Single-Phase Grid-Connected Inverter of a photovoltaic system in water and wind applications. E3S Web Conf. 2016, 1000004. [CrossRef] 
50. Borkowski, D. Control strategy for maximizing conversion efficiency of small hydropower plant. Tech. Trans. Elect. Eng. 2015, 112, 15-24.

51. Cervantes, M.; Andrée, G.; Klason, P.; Sundström, J. Flow Measurements in Low-Head Hydro Power Plants; Elforsk; Swedish Hydropower Centre: Stockholm, Sweden, 2012; Volume 12.

52. Borkowski, D. Maximum Efficiency Point Tracking (MEPT) for Variable Speed Small Hydropower Plant with Neural Network Based Estimation of Turbine Discharge. IEEE Trans. Energy Convers. 2017, 32, 1090-1098. [CrossRef]

53. Forbush, D.; Cavagnaro, R.J.; Polagye, B. Power-tracking control for cross-flow turbines. J. Renew. Sustain. Energy 2019, 11, 014501. [CrossRef]

Publisher's Note: MDPI stays neutral with regard to jurisdictional claims in published maps and institutional affiliations.

(C) 2020 by the authors. Licensee MDPI, Basel, Switzerland. This article is an open access article distributed under the terms and conditions of the Creative Commons Attribution (CC BY) license (http://creativecommons.org/licenses/by/4.0/). 